\title{
Compartment Syndrome of the Leg Requiring Emergent Fasciotomy Resulting from Multi-Drug Overdose
}

\author{
Charlie Srivilasa $^{* \#}$, Jeffrey W. Shupp ${ }^{\#}$, Anthony Shiflett ${ }^{\#}$ \\ Department of Surgery, MedStar Washington Hospital Center, Washington DC, USA \\ Email: *charlie.srivilasa@medstar.net, Jeffrey.w.shupp@medstar.net, Anthony.a.shiflett@medstar.net
}

Received December 7, 2013; revised January 5, 2014; accepted January 13, 2014

Copyright (C) 2014 Charlie Srivilasa et al. This is an open access article distributed under the Creative Commons Attribution License, which permits unrestricted use, distribution, and reproduction in any medium, provided the original work is properly cited. In accordance of the Creative Commons Attribution License all Copyrights (C) 2014 are reserved for SCIRP and the owner of the intellectual property Charlie Srivilasa et al. All Copyright (C) 2014 are guarded by law and by SCIRP as a guardian.

\begin{abstract}
A paucity of literature exists linking acute extremity compartment syndrome associated with cocaine or olanzapine overdose. LJ, a 38-year male, was initially seen at an outside hospital for acute encephalopathy and left lower extremity swelling shortly after cocaine and suspected olanzapine overdose. On presentation, totalcreatinine kinase levels were $>1000$ units/liter but quickly rose to 23,000 units/liter after 12 hours. He was transferred to a tertiary care center for surgical evaluation. Upon the exam, it was quickly determined that he had compartment syndrome and he was urgently taken to the operating room for a four-compartment lower extremity fasciotomy. Acute compartment syndrome is a limb threatening condition generally diagnosed clinically. Cocaine, a potent vasoconstrictor, is widely reported to cause rhabdomyolysis from ischemia of skeletal muscle tissue and direct toxicity to myocytes resulting in leakage of creatinine kinase. Other complications including cardiovascular, respiratory, neurological, and gastrointestinal disturbances have also been well documented. Olanzapine, an atypical antipsychotic, has also been reported to cause rhabdomyolysis. However, myositis with lower extremity compartment syndrome is a rare occurrence and requires quick diagnosis and aggressive treatment in order to achieve limb salvage. The potential causality of compartment syndrome from either cocaine, olanzapine, or both will be examined in this case report.
\end{abstract}

\section{KEYWORDS}

Compartment Syndrome; Olanzapine; Cocaine; Overdose; Rhabdomyolysis; Fasciotomy

\section{Background}

Drug induced focal myositis with subsequent compartment syndrome is a rare phenomenon. A limited number of case reports linking drugs to extremity compartment syndrome exist [1,2]. Statins have a well-known side effect of myopathy potentially leading to rhabdomyolysis [3]. Gemfibrozil alone has limited data for inducing myopathy but in combination with statins increases risk [4-7]. Similarly, cocaine and olanzapine both have evidence demonstrating potential side effects of myopathy and myositis. However, either alone or combined, there has been only one report of drug induced compartment

\footnotetext{
*Corresponding author.
}

\#All authors contributed equally the production of this case report. syndrome associated with either drug (cocaine). A literature review of PubMed reveals the following:

\section{Case Presentation}

A 38-year-old male was brought to an outside hospital emergency department by Emergency Medical Servicesafter being found unresponsive slumped against a wall with vomitus around him. No seizure activity was witnessed. Medical history abstracted from his spouse included a psychiatric disorder and depression. No surgical history was obtained. He had no known drug allergies. His wife denied any tobacco or alcohol use by her husband but admitted he used cocaine recently. His medications included Olanzapine for bi-polar disorder and un- 
specified anti-hypertensives.

He was given a total of $4 \mathrm{mg}$ of naloxone by EMS with no significant response. Initial reported GlascowComa Score was 3 with no signs of trauma. Hispupils were constricted but equal and reactive. Trachea was midline with clear breath sounds bilaterally. Heart sounds were normal with a soft, systolic murmur appreciated. His abdomen was non-tender, non-distended. Exam was significant for a swollen and tender left lower extremity with no erythema (Figure 1). Initial vital signs revealed significant hypertension with systolic blood pressures in the 180's and diastolic blood pressures 100 - $110 \mathrm{mmHg}$ range. Heart rate, respiratory rate, oxygen saturation and temperature were all within normal limits.

He was transferred to a large, urban level I trauma center for further management. Upon arrival, clinical exam revealed signs and symptoms of compartment syndrome. His lower extremity compartments were tight and painful to palpation. He grimaced in discomfort with passive motion of the extremity. Distal pulses were intact. Initial laboratory data revealed a creatinine kinase of 38,156 units/liter with urine positive for myoglobin. Aggressive intravenous hydration with crystalloid solution and a bicarbonate drip for renal protection were started. LJ was quickly taken to the operating room where a four compartment fasciotomy was performed revealing bulging but viable muscles (Figures 2 and 3). His post operative recovery was uneventful. The patient was transferred to the surgical intensive care unit after the operation. He returned to the OR 2 days later for delayed closure of his lateral wound. His medial wound underwent a staged closure with the first and second (final) procedures on post operative days 6 and 9, respectively. He was discharged in good condition on post operative day 10.

\section{Conclusions}

Cocaine is a common drug throughout the United States and across the world. It is second only to alcohol as the most used and abused drug. In 2009, the Drug Abuse Warning Network (DAWN) reported approximately 4.6 million emergency department visits pertaining to drug use. Of these, cocaine was attributed to around 420,000 visits or 137.7 visits per 100,000 [8].

As an amphetamine, cocaine exerts its vascular and cardiac effects by modifying the sympathetic nervous system. It also has neurological effects. Cocaine has three primary sympathomimetic mechanisms of action. It inhibits cathecholamine reuptake at sympathetic nerve terminals, increases sensitivity of adrenergic nerve endings to norepinephrine, and blocks sodium and potassium channels [9].

Cocaine induced muscle damage and rhabomyolysis has been widely reported, with a Pub Med search of "co-

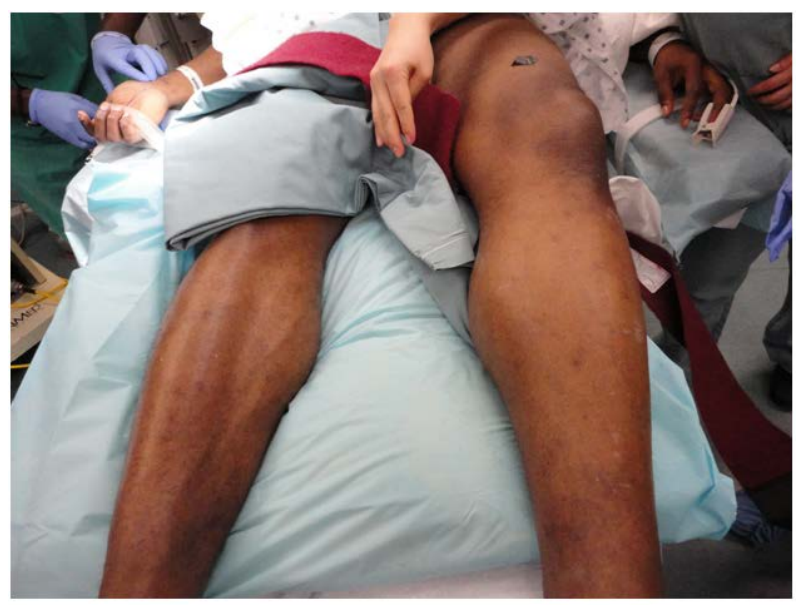

Figure 1. Swollen left lower extremity.

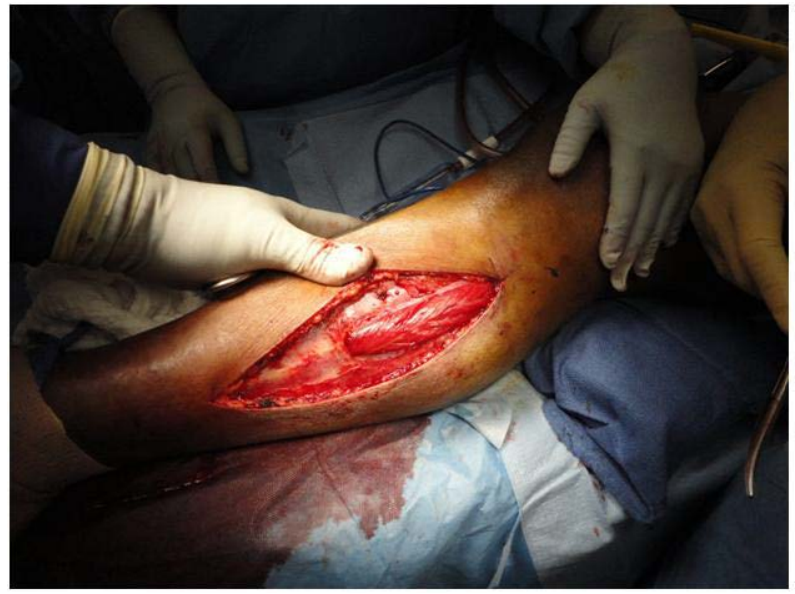

Figure 2. Bulging but viable muscles in lower leg compartments.

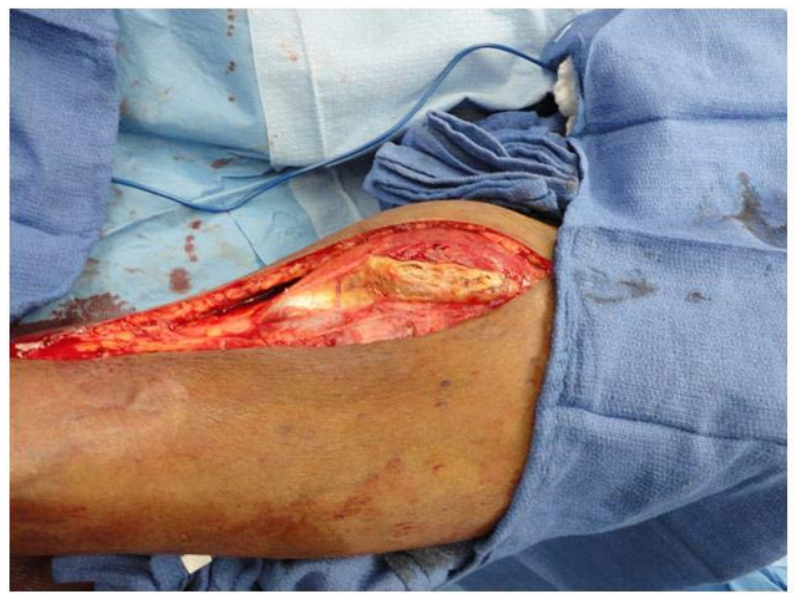

Figure 3. Bulging but viable muscles in lower leg compartments.

caine + rhabdomyolysis" revealing more than 50 articles. The mechanism of toxicity is multifactorial, likely involving intense vasoconstriction leading to ischemic 
damage and direct muscle toxicity. Cardiac, versus skeletal, muscle toxicity from cocaine abuse is better studied. Mechanisms for cardiotoxicity and arrhythmia generation that have been described include the blocking $\mathrm{K}^{+}$channels, increase in L-type $\mathrm{Ca}^{2+}$ channel current, and inhibition $\mathrm{Na}^{+}$influx during depolarization [10]. Correlation between cardiac and skeletal muscle damage mechanisms can likely be drawn. One case of compartment syndrome from cocaine abuse has been reported [11].

Olanzapine (Zyprexa) belongs in the class of atypical antipsychotics which exert their effects by modulating and having high affinity for 5-HT (serotonin) receptors. They have less affinity for $\mathrm{D}_{1}$ and $\mathrm{D}_{2}$ receptors, thus decreasing the incidence of extrapyramidal symptoms [12]. Olanzapine has been linked to rhabdomyolysis in a handful of case reports [13-20]. It is a rare complication, occurring in $<1 \%$ of uses [16]. Proposed mechanisms include increased cellular membrane permeability to calcium influx and prolonged muscle depolarization as well as direct muscle toxicity from buildup of serotonin within muscle cells [21-23]. However, in none of those cases did the severity of muscle break down progress to compartment syndrome.

Compartmentsyndrome is defined as an elevation of the interstitial pressure in a closed fascialcompartment that results in microvascular compromise [24]. Compartment syndrome can be both a cause and result of rhabdomyolysis. Ischemic and necrotic muscle results in inflammatory mediators and increased capillary basement membrane permeability. As a result, increased capillary leakage leads to increased tissue pressure. As pressure increases, ischemia is exacerbated by the decreased blood flow. Diagnosis of acute lower extremity compartment syndrome is clinical. Classically, pain out of proportion to exam is the first indication. Loss of pulses is often a late sign. Measurement of compartment pressures can also aid in diagnosis. Treatment is surgical and involves fasciotomies of the involved compartments to relieve pressure [24].

While both olanzapine and cocaine have been shown to cause muscle damage and rhabdomyolysis in isolated cases, compartment syndrome resulting from an overdose of either has only reported for one specific instance of cocaine abuse. Rhabdomyolysis resulting in compartment syndrome is also particularly rare. The authors theorize that combination of two muscle damaging drugs, olanzapine and cocaine, caused LJ's compartment syndrome. It was unlikely to be caused by positional damage because of the short time course of presentation. As such, it is important for clinicians to review a patient's medications when faced with a similar situation. While ultimately resulting in the same treatment, it is important to recognize the increased risk of combinations of muscle damaging drugs and to counsel patients on the signs and symptoms of compartment syndrome. Regardless of the mechanism, quick clinical diagnosis and treatment of extremity compartment syndrome is essential for limb salvage.

\section{Consent}

Written informed consent was obtained from the patient for publication of this case report and any accompanying images. A copy of the written consent is available for review by the Editor-in-Chief of this journal.

\section{REFERENCES}

[1] L. T. Chow and W. H. Chow, "Acute Compartment Syndrome: An Unusual Presentation of Gemfibrozil Induced Myositis,” Medical Journal of Australia, Vol. 185, No. 1, 1993, pp. 48-49.

[2] J. L. Walker, et al., "Spontaneous Compartment Syndrome in Association with Simvastatin-Induced Myositis," Emergency Medicine Journal, Vol. 25, No. 5, 2008, pp. 305-306. http://dx.doi.org/10.1136/emj.2007.055848

[3] M. R. Goldstein, "Statin-Induced Myositis: A Commonly Encountered or Rare Side Effect?” Current Opinion in Lipidology, Vol. 16, No. 6, 2005, pp. 640-647.

[4] G. J. Magarian, L. M. Lucas and C. Colley, "Gemfibrozil-Induced Myopathy,” JAMA Internal Medicine, Vol. 151, No. 9, 1991, pp. 1873-1874.

http://dx.doi.org/10.1001/archinte.1991.00400090143027

[5] Substance Abuse \& Mental Health Services Administration (Rockville, MD), "Myopathy and Rhabdomyolysis with Lovastatin Taken with Gemfibrozil," JAMA, Vol. 264, No. 23, 1990, pp. 2991-2992.

[6] J. A. Tobert, "HMG-CoA Reductase Inhibitors, Gemfibrozil, and Myopathy," American Journal of Cardiology, Vol. 75, No. 12, 1995, p. 862.

http://dx.doi.org/10.1016/S0002-9149(99)80435-4

[7] L. R. Pierce, D. K. Wysowski and T. P. Gross, "Myopathy and Rhabdomyolysis Associated with LovastatinGemfibrozil Combination Therapy,” JAMA, Vol. 264, No. 1, 1990, pp. 71-75.

http://dx.doi.org/10.1001/jama.1990.03450010075034

[8] S. Abuse and Mental Health Services Administration, C.f.B.H.S.a.Q.f.t.O.o.A.S., "The DAWN Report: Highlights of the 2009 Drug Abuse Warning Network (DAWN) Findings on Drug-Related Emergency Department Visits,” 2010.

[9] B. G. Schwartz, S. Rezkalla and R. A. Kloner, "Cardiovascular Effects of Cocaine,” Circulation, Vol. 122, No. 24, 2010, pp. 2558-2569. http://dx.doi.org/10.1161/CIRCULATIONAHA.110.9405 $\underline{69}$

[10] K. Phillips, et al., "Cocaine Cardiotoxicity: A Review of the Pathophysiology, Pathology, and Treatment Options," American Journal of Cardiovascular Drugs, Vol. 9, No. 3, 2009, pp. 177-196.

http://dx.doi.org/10.1007/BF03256574

[11] P. Vets, et al., "Rhabdomyolysis of the Left Upper Leg 
after Cocaine Abuse,” Journal Belge de Radiologie—Belgisch Tijdschrift voor Radiologie, Vol. 89, No. 3, 2006, pp. 158-159.

[12] K. J. Tulloch and P. Z. Zed, "Intramuscular Olanzapine in the Management of Acute Agitation," The Annals of Pharmacotherapy, Vol. 38, No. 12, 2004, pp. 2128-2135.

[13] J. R. Strawn, et al., "Hyperthermia and Rhabdomyolysis in an Adolescent Treated with Topiramate and Olanzapine," Journal of Child and Adolescent Psychopharmacology, Vol. 18, No. 1, 2008, pp. 116-118. http://dx.doi.org/10.1089/cap.2007.0101

[14] C. F. Hung, T. Y. Huang and P. Y. Lin, "Hypothermia and Rhabdomyolysis Following Olanzapine Injection in an Adolescent with Schizophreniform Disorder," General Hospital Psychiatry, Vol. 31, No. 4, 2009, pp. 376-378. http://dx.doi.org/10.1016/j.genhosppsych.2008.09.009

[15] J. Shuster, “Olanzapine and Rhabdomyolysis,” Nursing, Vol. 30, No. 9, 2000, p. 87. http://dx.doi.org/10.1097/00152193-200030090-00034

[16] S. Ribeyron, et al., "Olanzapine Induced Rhabdomyolysis and Serum Creatine Kinase Increase," La Revue de Médecine Interne, Vol. 30, No. 6, 2009, pp. 477-485. http://dx.doi.org/10.1016/j.revmed.2008.12.024

[17] W. S. Waring, J. Wrate and D. N. Bateman, "Olanzapine Overdose Is Associated with Acute Muscle Toxicity," Human \& Experimental Toxicology, Vol. 25, No. 12, 2006, pp. 735-740. http://dx.doi.org/10.1177/0960327106073832

[18] U. Baumgart, R. Schmid and H. Spiessl, "Olanzapine-
Induced Acute Rhabdomyolysis-A Case Report," Pharmacopsychiatry, Vol. 38, No. 1, 2005, pp. 36-37.

http://dx.doi.org/10.1055/s-2005-837770

[19] C. J. Rosebraugh, et al., "Olanzapine-Induced Rhabdomyolysis,” Annals of Pharmacotherapy, Vol. 35, No. 9, 2001, pp. 1020-1023.

http://dx.doi.org/10.1345/aph.10370

[20] P. Karakaya, et al., "Rhabdomyolysis Associated with Olanzapine Treatment in a Child with Autism," Pediatric Emergency Care, Vol. 26, No. 1, 2010, pp. 41-42. http://dx.doi.org/10.1097/PEC.0b013e3181c39a22

[21] M. Molen-Eijgenraam, J. T. Blanken-Meijs, M. Heeringa and A. C. van Grootheest, "Delirium Due to Increase in Clozapine Level during an Inflammatory Reaction," Nederlands Tijdschrift voor Geneeskunde, Vol. 145, No. 9, 2001, pp. 427-430.

[22] W. Koren, E. Koren, N. Nacasch, M. Ehrenfeld and H. Gur, "Rhabdomyolysis Associated with Clozapine Treatment in a Patient with Decreased Calcium-Dependent Potassium Permeability of Cell Membranes,” Clinical Neuropharmacology, Vol. 21, No. 4, 1998, pp. 262-264.

[23] H. Y. Meltzer, P. A. Cola and M. Parsa, "Marked Elevations of Serum Creatine Kinase Activity Associated with Antipsychotic Drug Treatment," Neuropsychopharmacology, Vol. 15, No. 4, 1996, pp. 395-405. http://dx.doi.org/10.1016/0893-133X(95)00276-J

[24] N. Shah and J. R. Durham, "Compartment Syndrome, in ACS Surgery: Principles \& Practice,” Decker Publishing Inc., Philadelphia, 2012, pp. 1547-1616. 